\title{
Coordination and cooperation in asymmetric commons dilemmas
}

\author{
Marco A. Janssen · John M. Anderies • \\ Sanket R. Joshi
}

Received: 4 November 2009 / Accepted: 18 April 2011

(C) Economic Science Association 2011

\begin{abstract}
In this paper we discuss laboratory experiments that address the problem of self-governance in an asymmetric commons dilemma. Small-scale irrigation systems that provide food for hundreds of millions of people around the world are probably the most common example of such dilemmas. Here, we formulate an abstract dilemma in which subjects make both a decision about investment in the provision of infrastructure associated with the use of a resource and about how much to extract from the common-pool resource made available by this infrastructure. The impact of inherent asymmetry in irrigation systems on the provision of a resource and the impact of communication on the capacity of the group to solve the two-level commons dilemma of cooperation and coordination based on the analysis of the experimental data are discussed.
\end{abstract}

Keywords Common-pool resources · Asymmetry · Irrigation · Fairness · Real-time experiment

JEL Classification C91 · C92 - Q25 - Q57

Electronic supplementary material The online version of this article

(doi:10.1007/s10683-011-9281-9) contains supplementary material, which is available to authorized users.

M.A. Janssen $(\varangle) \cdot$ J.M. Anderies

School of Human Evolution and Social Change, Center for the Study of Institutional Diversity, Arizona State University, PO Box 872402, Tempe, AZ 85287-2402, USA

e-mail: Marco.Janssen@asu.edu

J.M. Anderies

School of Human Evolution and Social Change, Center for the Study of Institutional Diversity,

School of Sustainability, Arizona State University, PO Box 872402, Tempe, AZ 85287-2402, USA

S.R. Joshi

Center for the Study of Institutional Diversity, School of Computing and Informatics, Arizona State University, PO Box 872402, Tempe, AZ 85287-2402, USA 


\section{Introduction}

The emergence of large, complex societies has puzzled generations of social scientists. One of the challenges large societies face is the need to develop ways to sustain cooperation with non-kin in large groups. Irrigation systems have long drawn the attention of scholars interested in such questions as they are so often associated with complex societies and are archetypal examples of human cooperative systems. Specifically, it has often been suggested that irrigation systems require a central authority to solve coordination problems associated with their operation. Wittfogel (1957) argued that such central control was indispensable for the functioning of larger irrigation systems and hypothesized that some state-level societies have emerged as a necessary side effect of solving problems associated with the use of large-scale irrigation. However, there are numerous examples of complex irrigation systems that have evolved without central coordination (Hunt 1988; Lansing 1991; Ostrom 1992).

A fundamental challenge facing irrigation systems and other complex socialecological systems is how to solve two related collective action problems: 1) the provision of infrastructure necessary to use a resource (the physical irrigation infrastructure itself) and 2) the asymmetric common-pool resource dilemma in which the relative positions of "head-enders" and "tail-enders" generate asymmetric access to the resource (Ostrom and Gardner 1993). If actors behave as rational, selfish economic agents, it is difficult to imagine how irrigation infrastructure would ever be created in the first place. Even if the challenging problem of providing the infrastructure was solved, there are always incentives for users to over-appropriate from the resource it generates. This is especially true if the spatial configuration of the system privileges some users; the head-ender who has first access to water may not necessarily share with the tail ender. The sensitivity of the performance of irrigation systems to the behavior of such selfish rational actors leads to the question of why so many self-organized irrigation systems exist and persist for so long (Hunt 1988; Lansing 1991; Ostrom 1992).

Although difference in access to resources is a common challenge to the successful governance of common-pool resources, conventional experiments aimed at addressing commons dilemmas assume symmetrical access to the resource (but see Rapoport 1997; Budescu and Au 2002). This paper presents the results of our efforts to explore these questions using laboratory experiments explicitly designed to address the problem of self-governance in an asymmetric commons dilemma. We formulate an abstract dilemma in which subjects first make a decision concerning how much to invest in infrastructure necessary for the provision of the common-pool resource. This investment decision determines the maximum flow rate of the common-pool resource which is then available for players to extract. The second set of decisions involves the rate at which players extract from the common-pool resource stream. For these latter decisions, subjects are faced with an asymmetry problem because their position (spatial configuration) influences the order in which they can extract resources. Only the flow that is not appropriated by upstream players is available for downstream players. This sequence of provisioning and coordination decisions is repeated for 10 rounds. Between rounds subjects can communicate and indirect punishment can be used by 
downstream players who may decide to invest less in the public infrastructure in order to negatively influence the ability of upstream subjects to appropriate the resource.

What types of outcomes should we expect in such situations? A brief review of relevant experimental findings provides a basis for our conjectures which we test using the experimental setting described above. The first key finding of interest here is that the average initial contribution in provision dilemmas (e.g. public goods games) in laboratory experiment settings is generally observed to be around $50 \%$ of each player's total endowment (Isaac and Walker 1988a; Isaac et al. 1994; Ledyard 1995). Over time, this level changes depending on the marginal per capita return (mpcr) and the group size. A low mpcr leads to rapid convergence to a situation of almost no contributions to the public good while a relatively high $\mathrm{mpcr}$ has been shown to generate a pattern in which the contribution level stabilizes around $50 \%$ of the total endowment. Larger group sizes have also been found to lead to larger per capita contributions (Isaac and Walker 1988a).

While public good experiments typically use linear payoff functions, here the provision of the common resource is a nonlinear function that exhibits a threshold effect. In this case, if the total investment exceeds the threshold, the amount (measured in terms of the flow of the common-pool resource it provides) of public infrastructure that results increases very rapidly. Likewise, if the investment level is below the threshold, little or no public infrastructure is produced. In such cases, Croson and Marks (2000) have shown that the higher the return from the public good in relation to the threshold level, the higher the investment in the public good.

Other experiments that assume asymmetry in the capacity of agents to extract from the common-pool resource have led to the observation that upstream participants appropriate more of the common-pool resource and that downstream participants, in fact, expect them to do so (Rapoport 1997; Budescu and Au 2002). Thus, biophysical contexts that generate situations in which participants appropriate from the common resource sequentially will lead to inequality in the rates of resource extraction across participants (Janssen et al. 2011).

Another frequently studied component of collective action in experiments is communication. For example, in experiments with public good provision dilemmas it has been shown that allowing communication induces an increase in contributions compared to the no communication condition (Isaac and Walker 1988b). Bochet et al. (2006) found that chat room communication, as we use in our experiment, is almost as effective as face-to-face communication. Similarly, allowing communication increases cooperation in common-pool resource dilemmas (Ostrom et al. 1992; Hackett et al. 1994; Janssen et al. 2010). Finally, there has been considerable research in the use of costly punishment in public goods and common-pool resources (Ostrom et al. 1992; Fehr and Gächter 2000; Janssen et al. 2010). This work shows that participants will engage in sanctioning that reduces the earnings of others, and that the existence of costly punishment increases the level of cooperation. In the experiments described here, downstream participants can punish upstream participants by reducing their investment in the provision of public infrastructure.

Based on these findings from earlier experimental studies and our interest in the combined problem of provision and asymmetric extraction, we formulate the following conjectures: 
Conjecture 1 Subjects will invest significantly in infrastructure required for the provision of a common-pool resource.

In the Nash equilibria for our experimental design (discussed in the next section) the investment level in the public infrastructure is zero. Downstream participants will not invest in the public infrastructure if they expect the upstream participants to take all the resources. As a consequence nobody will expect to gain in investing in the public infrastructure. However, from public good experiments, which do not exhibit the potential for asymmetric access to the resource flows generated by the public infrastructure, we know that participants do invest a significant amount, and this amount increases when there is the option for communication (e.g. Balliet 2010). That's why we expect, that although the NE predicts zero investment, that there will be a significant investment in the provision phase of the experiment.

Conjecture 2 Tail-ender subjects will reduce investments in public infrastructure provision if they do not receive a fair share of the resulting resource flows.

Subjects who are at the end of the chain of access to the common-pool resource have the ability to react in the next round. From the studies on costly punishment in common-pool resource contexts, we expect that subjects will be willing to reduce their investments and, therefore, reduce the flow of common-pool resources for all subjects in the next round (Ostrom et al. 1992).

Conjecture 3 Upstream subjects will exploit asymmetry in the system and appropriate more from the common-pool resource than downstream subjects.

The upstream subjects have first choice to resource flows and the downstream subjects can only indirectly punish the upstream subjects by investing less in the next round (Rapoport 1997).

Conjecture 4 Conjectures 2 and 3 taken together imply that the specific biophysical context captured by our experimental design may lead to a situation in which public infrastructure is systematically under-provided, and system performance is thus reduced.

If the basic patterns observed in previous experimental work mentioned above are robust, subjects will be locked into a situation in which they are unable to solve a dilemma which, as mentioned in the Introduction, seems to have been solved by many groups in the past.

The laboratory experiment described here was specifically designed to test these conjectures and to explore the relationship between the extent to which they hold and different aspects of the infrastructure. It is our hope that our testing of these conjectures will contribute to our understanding of how social systems associated with complex irrigation and biophysical infrastructure survive despite the collective action challenges they face. The details of the experimental context, specific questions, and data gathered are presented in the next section. The statistical analysis of the data 
Table 1 Common resource level as a function of the total investment of two players

\begin{tabular}{ll}
\hline Total token investment & Common resource \\
\hline 0 & 0 \\
1 & 0 \\
2 & 0 \\
3 & 0 \\
4 & 0 \\
5 & 0 \\
6 & 0 \\
7 & 0 \\
8 & 1 \\
9 & 2 \\
10 & 6 \\
11 & 12 \\
12 & 20 \\
13 & 28 \\
14 & 33 \\
15 & 36 \\
16 & 38 \\
17 & 39 \\
18 & 39 \\
19 & 40 \\
20 & 40 \\
\hline
\end{tabular}

along with qualitative analysis of some patterns that emerge from the data follows. Finally we discuss several additional general implications of this work.

\section{Experimental design}

The experiment takes the form of an $N$-player game. We have performed experiments both for $N=2$ and $N=5$ but to simplify the exposition, we will explain the design for $N=2$. The two players occupy different positions: $\mathrm{A}$ and $\mathrm{B}$. The players have to make two decisions. First they have to make a decision concerning how much to invest in public infrastructure. In each round players receive 10 tokens, each worth $\$ 0.1$, that can be used for investment. The investment of the $i$ th player is denoted as $y_{i}$ and the total investment in the public infrastructure, the sum of $y_{i}$ over $i$ is denoted by $y$. The production function for public infrastructure depends on $y$.

In order to capture some aspects of the nature of irrigation systems - namely increasing returns to scale for lower levels of investment and decreasing returns for higher levels, we employ a sigmoidal production function as demonstrated in Table 1 . We have chosen a scaling that produces a range that makes it impossible for one person to create public infrastructure without the help of others. For example, to create a head gate for an irrigation system one needs to have a sufficiently large group of people working together at the same time. One person cannot bend a river. 
Hence cooperation is required to generate a level of public infrastructure that generates a positive return on investment. The amount of public infrastructure generated as a function of joint investment is shown in Table 1. If both players invest 10 tokens, the common-pool resource provided by the public infrastructure reaches a level of 40 units. There is an inflection point at $y=12$. For investments from $0-12$, the production function exhibits increasing returns and for investments over 12, the returns to scale are decreasing. For $N=5$, we use the same function, but then the inflection point is 30 (equivalent to the two-payer game with average per capita investment of 6 tokens).

In order to avoid biasing subjects for a particular context, we do not present the experiment to the participants as an irrigation experiment but, rather, as a game more in line with their experience. To explain the game to the subjects we describe it as a game of downloading digital files where subject A has priority access to the available bandwidth (the common-pool resource) over subject B. The experiment utilizes a dashboard to allow subjects to make decisions and display information about the experiment. In each round, before downloading can begin, subjects make a decision about how many tokens to invest in creating bandwidth. Subjects are informed about how much each of the subjects invested, and how much bandwidth was created based on their total investment. Next, there is a period of 100 seconds during which subjects can download files. Using the dashboard, subjects click on images of files to start downloading and they see an animation of the downloading process. They are shown how much bandwidth is available for each subject and how much time is left in the downloading period (see online Appendix). The real time interaction is purposely chosen to include the need for coordination to solve the asymmetry problem.

The public infrastructure that results from the total investment is bandwidth (kbs) that the players can use in the second part of the round. Each player can download a maximum of 10 files of $250 \mathrm{~kb}$ each during a period of 100 seconds. Player A has first access (i.e. is upstream) to the bandwidth generated $\mathrm{B}_{\mathrm{T}}$. The maximum downloading speed of each player is $25 \mathrm{kbs}$. The amount of bandwidth which is not used by player $\mathrm{A}$ is available for player B. Thus if $40 \mathrm{kbs}$ is available, and player A is downloading, only $15 \mathrm{kbs}$ is available for player B.

The monetary returns depend on the production function as a function of the number of files downloaded. When only a few files are downloaded no tokens are earned. This resembles the case in which a limited amount of water is received by a farmer which is insufficient to grow a crop. When the number of files downloaded increases, the number of tokens earned increases sharply. This reflects the fact that enough water has been collected to grow crops. If more than 7 files are downloaded, the extra reward is marginal. This reflects the fact that beyond a certain amount of water there is saturation for the crop growth. Thus, if ten files are downloaded, 20 tokens are earned. The total earnings of a player is the number of tokens not invested in the common resource plus the number of tokens earned by downloading files.

In order to derive the Nash and social equilibria for this experimental design we assume that participants have zero reaction time and maximize their material earnings. The Nash equilibrium is derived in the following way. If there is a positive bandwidth, player A, the upstream participant, will use this bandwidth to download files. The maximum number of files that can be downloaded is 10 files. A file of 


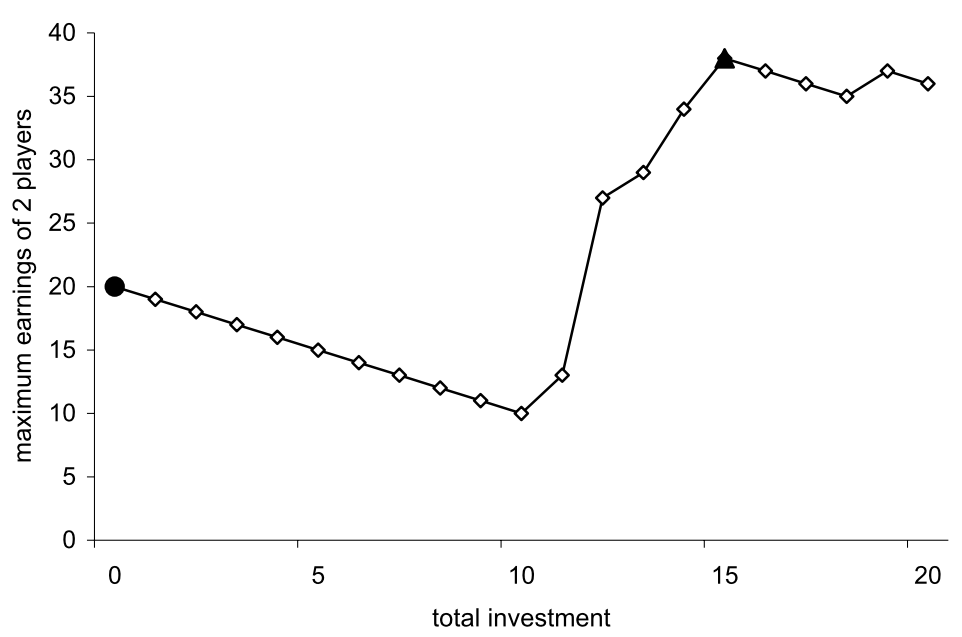

Fig. 1 Maximum earnings (in tokens) for the two players if they cooperate and coordinate as a function of total investment. The dot is the Nash equilibrium, and the triangle the cooperative equilibrium

$250 \mathrm{~kb}$ can be downloaded in 10 seconds if the available bandwidth is at least $25 \mathrm{kbs}$. Thus in the 100 seconds available, player A can download exactly a maximum of 10 files, and earn 20 tokens. What would be the maximum earnings for player B in this case? A maximum of $15 \mathrm{kbs}$ would have been available, leading to a download of 6 files and earnings of 15 tokens. Hence player B would be willing to invest 9 or 10 tokens in the public good. Knowing this, player A has an incentive to free-ride on player B and reduce her investment level to 3-4 tokens in order to reach a total investment target of 13 tokens and generate a bandwidth of $28 \mathrm{kbs}$ (lowest increment above 25). In other words, if player A expects there is sufficient bandwidth for more than one player to download files, player A will reduce her investment to increase her earnings. Knowing this, downstream players will not invest in the public infrastructure. As a consequence there is not sufficient bandwidth for player A to gain from investments in the public infrastructure and player A will abstain from investments in the common bandwidth as well. The Nash equilibrium for selfish rational agents is thus a case in which neither player invests in the common bandwidth and both keep their entire endowment.

For the cooperative equilibrium we define which strategies lead to the highest combined payoff independent of the distribution of the earnings. For each level of joint investment we know the bandwidth available during the 100-second download period and we can calculate which combination of files downloaded by player A and B leads to the highest joint earnings. After we have done this for all possible levels of the infrastructure we derive the payoffs for a cooperative strategy during the downloading phase as a function of the investment in public infrastructure (Fig. 1). An investment of 15 tokens by both players together in the public infrastructure will allow them to download a total of 13 files yielding a total return of 38 tokens (peak on curve in Fig. 1). There are twelve possible ways in which this can be achieved. First there are six ways in which players $\mathrm{A}$ and $\mathrm{B}$ can invest a total of 15 tokens: $10+5,9+6,8+7,7+8,6+9$, and $5+10$. Then A and B can coordinate their 
Table 2 Tokens earned as a function of the number of files downloaded

\begin{tabular}{lc}
\hline Number of files downloaded & Tokens earned \\
\hline 0 & 0 \\
1 & 0 \\
2 & 0 \\
3 & 1 \\
4 & 4 \\
5 & 10 \\
6 & 15 \\
7 & 18 \\
8 & 19 \\
9 & 19 \\
10 & 20 \\
\hline
\end{tabular}

downloading so that A or B downloads 7 files while the other downloads 6 files leading to $18+15=33$ additional tokens (see Table 2). The case in which A and B respectively invest 9 and 6 tokens and download 7 and 6 files (or vice versa) generates the most equitable distribution.

The theoretical equilibria are shown in Fig. 1. In practice players loose some downloading capacity due to the reaction time between clicking on the boxes and will typically download at least one file less than this maximum. The irregular shape of Fig. 1 is caused by the discrete units of the files and the bandwidth lost when player $\mathrm{A}$ is not downloading and $\mathrm{B}$ has access to more than $25 \mathrm{kbs}$ of which B can only use $25 \mathrm{kbs}$. In summary, the cooperative equilibrium yields 38 tokens.

If we apply the same reasoning (with zero reaction time) to the 5-player case, the Nash equilibrium will again be no investment in the public infrastructure by each player. This will lead to 50 tokens for the five players together, the 10 tokens of the original endowment for each player.

The cooperative optima for 5 players are investment combinations of 37 or 38 tokens with total earnings of 104 tokens (there are many permutations of 5 players investing a total of 37 or 38 tokens). With an investment of 37 tokens the bandwidth is $36 \mathrm{kbs}$, leading to 5 combinations of collecting 91 tokens from downloading 8 files by one player and 7 files by the others. With an investment of 38 tokens the bandwidth is $37 \mathrm{kbs}$ leading to 10 combinations of collecting 92 tokens from downloading 8 files by two players and 7 files by three players.

The 2-player and 5-player games have the same incentive structure. Both require more than $60 \%$ investment of the groups initial token endowment to generate a positive net return from the public infrastructure, both have a Nash equilibrium in which there is no investment in the public infrastructure and in which players can double their initial endowment through cooperation. As we will see in the results, coordination is more difficult in a larger group size.

Before the subjects can start the experiment, they must go through a number of instructions which are followed by a quiz. They can only start when all quiz questions are answered correctly. The experiment starts with 2 practice rounds that do not count toward player earnings followed by 10 rounds which are played for mone- 
Table 3 Summary of the experimental design

\begin{tabular}{|c|c|c|c|}
\hline Label: & 2 person & 5 person & 5 person $(b)^{\mathrm{a}}$ \\
\hline Number of subjects & $\begin{array}{l}10 \text { groups }= \\
20 \text { subjects }\end{array}$ & $\begin{array}{l}6 \text { groups }= \\
30 \text { subjects }\end{array}$ & $\begin{array}{l}5 \text { groups }= \\
25 \text { subjects }\end{array}$ \\
\hline Positions & $\mathrm{A}$ and $\mathrm{B}$ & $\mathrm{A}, \mathrm{B}, \mathrm{C}, \mathrm{D}$, and $\mathrm{E}$ & $\mathrm{A}, \mathrm{B}, \mathrm{C}, \mathrm{D}$ and $\mathrm{E}$ \\
\hline $\begin{array}{l}\text { Length of time to } \\
\text { download file }\end{array}$ & $\begin{array}{l}\text { Depends on available } \\
\text { bandwidth }\end{array}$ & $\begin{array}{l}\text { Depends on available } \\
\text { bandwidth }\end{array}$ & $\begin{array}{l}\text { Depends on available } \\
\text { uninterrupted } \\
\text { positive bandwidth }\end{array}$ \\
\hline $\begin{array}{l}\text { Nash equilibrium: } \\
\text { Average earnings } \\
\text { per person }\end{array}$ & 10 tokens & 10 tokens & 10 tokens \\
\hline $\begin{array}{l}\text { Social optimum: } \\
\text { Average earnings } \\
\text { per person }\end{array}$ & 19 tokens & 20.8 tokens & 20.8 tokens \\
\hline
\end{tabular}

a 5 person experiment where partly downloaded files are lost if an upstream participants completely blocked access to the bandwidth by downloading a file

tary returns. Before each round, the players can exchange text messages among those within the same group for 60 seconds. The detailed instructions are provided in online Appendix.

We used three treatments in this study (Table 3). We performed experiments with 2 and 5 subjects to explore the consequences of larger group sizes on the ability of groups to solve this collective action problem. In the 5 person experiments, we also included another treatment, the third treatment in our study, where partly downloaded files were lost if an upstream subject completely blocked access to the bandwidth by downloading a file. This third treatment is included to mimic the practical importance of delivering water at the right time to crops in irrigation systems. For example, for most rice varieties, there is a critical period during which nursery plants grown from seeds are ready to be transplanted into the main fields. During this time about one month after seeds are planted, a high volume of water is required in a very short period. Otherwise, crop yields will be severely impacted (Cifdaloz et al. 2010).

The third treatment has the same equilibria as the second treatment, but we will see from the results that the complexity associated with coordinating the allocation of access to bandwidth in this situation is increased.

\section{Experimental results}

The experiments were performed between November 2007 and February 2008 at Arizona State University. The subjects were recruited from a database of undergraduate students who had indicated that they were willing to participate in experiments with human subjects. This database consists of students from all majors, and invitations were sent out to a random sample of the whole population when an experiment was 
Table 4 Average number of tokens invested per round per person (standard deviation). The $p$-statistic of the Wilcoxon Matched-Pairs Signed-Ranks Test between position A and B in the 2-person game is 0.004 (10 independent observations)

\begin{tabular}{llll}
\hline & 2 person & 5 person & 5 person (b) \\
\hline A & $8.93(0.79)$ & $8.75(0.83)$ & $9.08(0.95)$ \\
B & $8.25(1.06)$ & $8.48(1.09)$ & $9.04(1.56)$ \\
C & & $8.48(1.11)$ & $7.22(2.56)$ \\
D & & $7.78(2.06)$ & $8.6(1.74)$ \\
E & & $6.72(3.51)$ & $7.24(2.90)$ \\
\hline
\end{tabular}

Table 5 Average number of files downloaded per round per person (standard deviation). The $p$-statistic of the Wilcoxon Matched-Pairs Signed-Ranks Test between position A and B in the 2-person game is $<0.001$ (10 independent observations)

\begin{tabular}{llll}
\hline & 2 person & 5 person & 5 person (b) \\
\hline A & $6.95(1.33)$ & $6.95(2.31)$ & $5.44(1.23)$ \\
B & $5.05(0.90)$ & $6.8(1.72)$ & $5.78(1.74)$ \\
C & & $5.42(1.36)$ & $4.32(1.95)$ \\
D & & $5.42(2.38)$ & $4.62(1.76)$ \\
E & & $3.22(2.20)$ & $3.42(1.63)$ \\
\hline
\end{tabular}

Table $6 p$-values of Wilcoxon Matched-Pairs Signed-Ranks Test statistics for the number of downloaded files at the different positions. We both mention the regular 5 player game (6 observations per position) and the 5 player game with need for uninterrupted bandwidth (after the "/" sign) (5 observations)

\begin{tabular}{lllll}
\hline & $\mathrm{A}$ & $\mathrm{B}$ & $\mathrm{C}$ & $\mathrm{D}$ \\
\hline $\mathrm{B}$ & $0.84 / 1.00$ & & & \\
$\mathrm{C}$ & $0.56 / 0.13$ & $0.44 / 0.25$ & & \\
$\mathrm{D}$ & $0.16 / \mathbf{0 . 0 6}$ & $0.22 / \mathbf{0 . 0 6}$ & $1.00 / 0.81$ & \\
$\mathrm{E}$ & $\mathbf{0 . 0 3 / 0 . 0 6}$ & $\mathbf{0 . 0 3 / 0 . 0 6}$ & $\mathbf{0 . 0 3} / 0.31$ & $\mathbf{0 . 0 6 / 0 . 0 6}$ \\
\hline
\end{tabular}

scheduled. Based on exit surveys, of the 75 persons that participated in the experiments reported in this paper, $44 \%$ were female and the average age was 19.2 years. Average earnings were $\$ 18.40$, including a show up bonus of $\$ 5$ plus payments for their play (made in private) for experiments with an average duration of 70 minutes. The individual minimum and maximum earnings were $\$ 10.00$ and $\$ 26.40$, respectively.

Tables 4, 5, 6 and 7 present the basic statistics related to experimental outcomes. Table 4 shows that subjects invest a considerable number of tokens in the public infrastructure (bandwidth), although those who are 'downstream' invest somewhat less than those upstream in the 2-person game. The $p$-statistic of the Wilcoxon MatchedPairs Signed-Ranks Test between position A and B in the 2-person game is 0.004 (10 independent observations). The differences between positions in the 5-person ex- 
Table 7 Number of tokens earned per round per person (standard deviation)

\begin{tabular}{llcc}
\hline & 2 person & 5 person & 5 person (b) \\
\hline A & $17.18(2.83)$ & $16.48(3.94)$ & $13.68(3.18)$ \\
B & $12.18(3.76)$ & $16.85(2.61)$ & $14.22(3.15)$ \\
C & & $13.35(4.21)$ & $11.94(2.99)$ \\
D & & $14.4(3.77)$ & $11.3(2.38)$ \\
E & & $9.4(3.70)$ & $7.96(2.49)$ \\
\hline
\end{tabular}

periments using the Wilcoxon Matched-Pairs Signed-Ranks Test are not significant (using 6 (5 person) and 5 (5 person $b$ ) independent observations of the average investment levels of 10 rounds). In Tables 5 and 6 we see that the number of files downloaded is quite unequally distributed. Position A downloads about twice the amount compared to position E. For the two person experiment, the difference in the number of files downloaded between the two subjects is significant $(p<0.001)$ using the Wilcoxon Matched-Pairs Signed-Ranks Test. For the 5 person experiments these differences are significant $(p<0.1)$ between persons $\mathrm{E}$ and A, B, C and D. For the 5 person treatment in which partly downloaded files can be lost, there are significant differences between persons $\mathrm{E}$ and $\mathrm{A}, \mathrm{B}$ and D, and between D, A and B. This provides support for Conjecture 3 (upstream-downstream asymmetry).

These investment-patterns and downloads lead to considerable inequality in earnings between the upstream and downstream subjects (Table 7). In the two person experiments the $p$-value if the Wilcoxon Matched-Pairs Signed-Ranks Tests is smaller than 0.002 using 10 independent observations. In the 5 person experiments subjects in position E received even less than the Nash equilibrium of 10 tokens in which none of the subjects invest in public infrastructure. For the 5 person experiment with allow interrupted downloads, the earnings by the subject in position $\mathrm{E}$ is significant ( $p$-value $<0.1)$ lower than other positions using the Wilcoxon Matched-Pairs Signed-Ranks Test with 6 independent observations. For the 5 person experiment that does not allow interrupted downloads, the earnings of position A is significant ( $p$-value $<0.1$ ) higher than those of position D and E using the Wilcoxon Matched-Pairs Signed Ranks Test with 5 independent observations. The same holds for earnings of the subject in position B compared to the earnings of the subject in position E.

Another significant pattern that emerged is that the level of public infrastructure generated tended to increase over time. The bandwidth for the two player case is high for all ten rounds. On the other hand, because coordination in the 5 person player treatments is more difficult, the level of bandwidth is lower and more irregular over the rounds. Figure 2 supports Conjecture 1 which posits that investments in the public infrastructure are substantial and remain so over time.

Similarly, the level of earnings per person also tends to increase over time (Fig. 3). Initially, earnings were about 12 tokens per round but increased over time to 15 tokens. Note that the level of earnings for the 5-person (b) experimental treatment exhibits considerably lower earnings (due to lost files and more complex coordination), except for position E (Table 7).

On average the upstream subjects (position A) achieve much higher earnings than subjects downstream (position E). This is especially true at the beginning of the ex- 


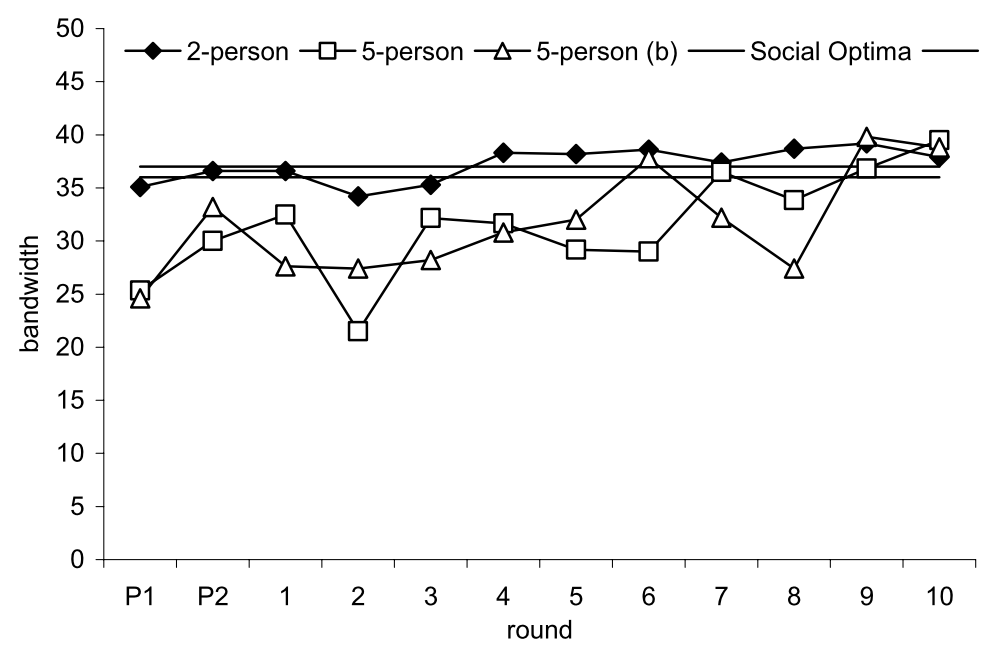

Fig. 2 Average level of bandwidth for the three treatments. The social optimum for the 2-person treatment is $36 \mathrm{kbs}$ and the bandwidth levels for the social optima of the 5-person treatments are 36 and $37 \mathrm{kbs}$

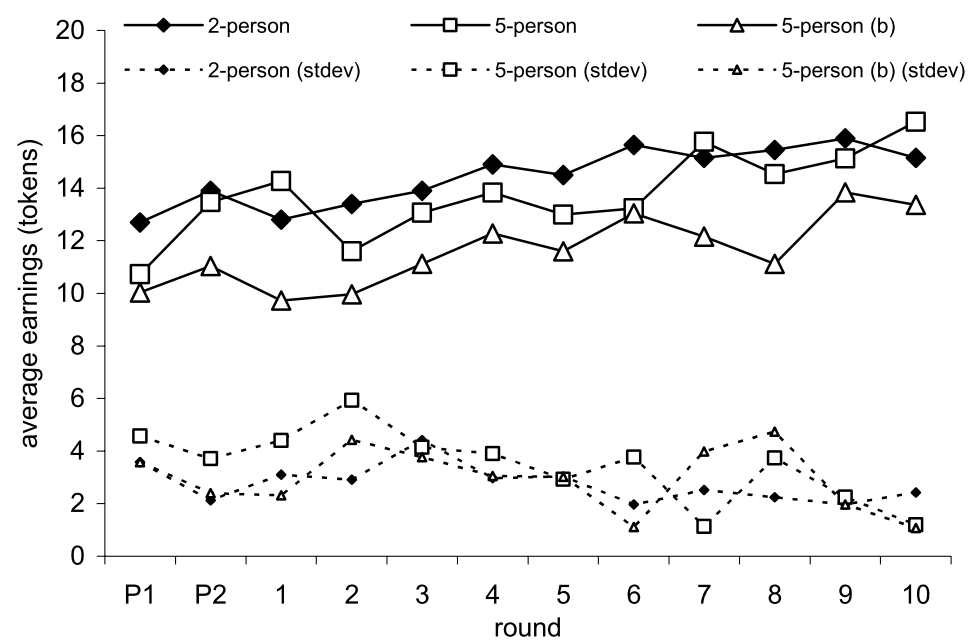

Fig. 3 Average level and standard deviation of earnings for the three treatments

periment where the inequality in the number of files downloaded is substantial as reflected in a Gini coefficient of between 0.4 and 0.45 (Fig. 4). However, over the course of the rounds we see that the level of inequality decreases. The 5 person (b) experimental treatment leads to a lower Gini coefficient as compared to the less challenging 5 person experiment. Later we will show that the 5 person (b) experimental treatment leads to an increased need for coordination and requires more equal distribution of the files in order to maintain group investments in the public infrastructure.

Figures 5, 6 and 7 show the data for the actual level of group investment and earnings in relation to the optimal cooperative solutions. The data presented in Fig. 5 


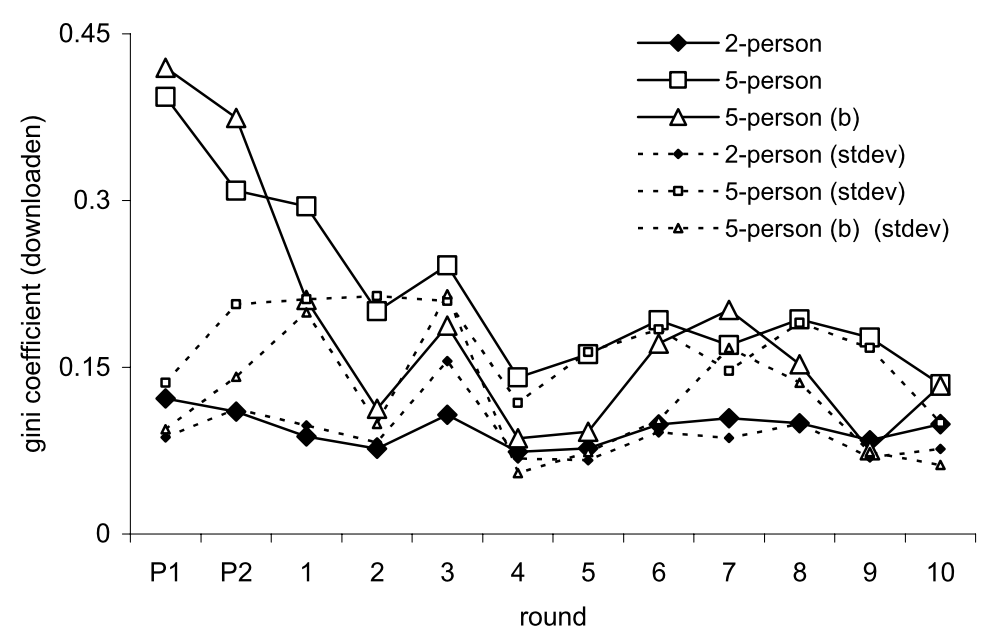

Fig. 4 Average level and standard deviation of Gini coefficient of number of files downloaded

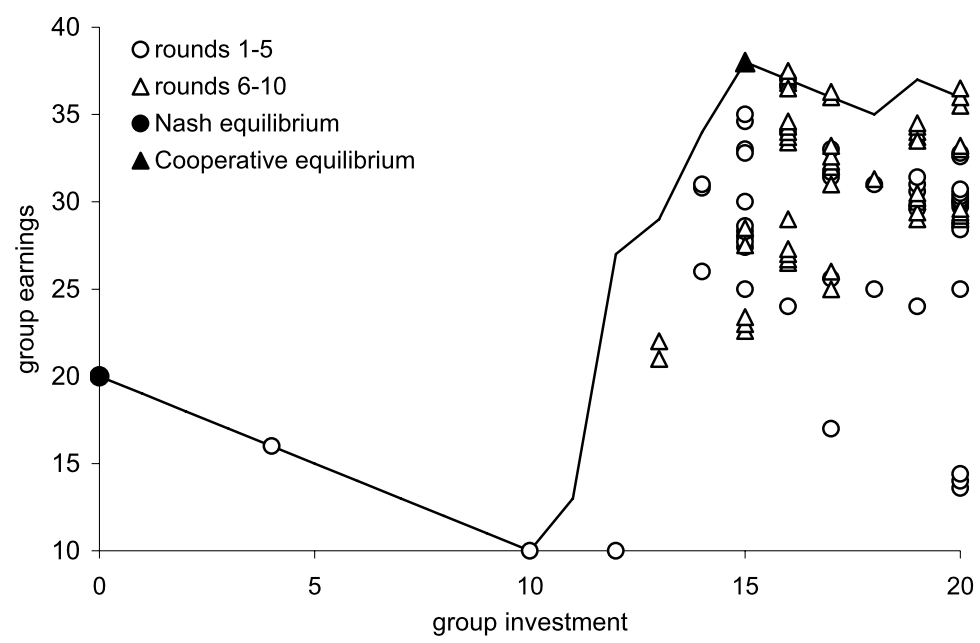

Fig. 5 The relation between the group investment and group earnings for each round of the two person experiments. Distinction is made between data from first half and second half of the experiment

shows that in many rounds of the two-person experiment, the groups approach the cooperative maximum level given the level of investment. In 6 of the 100 cases the group earnings were 37 tokens, and in 5, the earnings were 36 tokens (the optimal is 38). This is especially true in the second half of the experiment (rounds 6-10). One reason for being below the cooperative optimum is the lack of precise coordination so that some individuals in position A download an extra file with a lower marginal benefit for the group total compared with the situation in which another subject had downloaded that same file (this is due to the nonlinearity of the payoff function). 


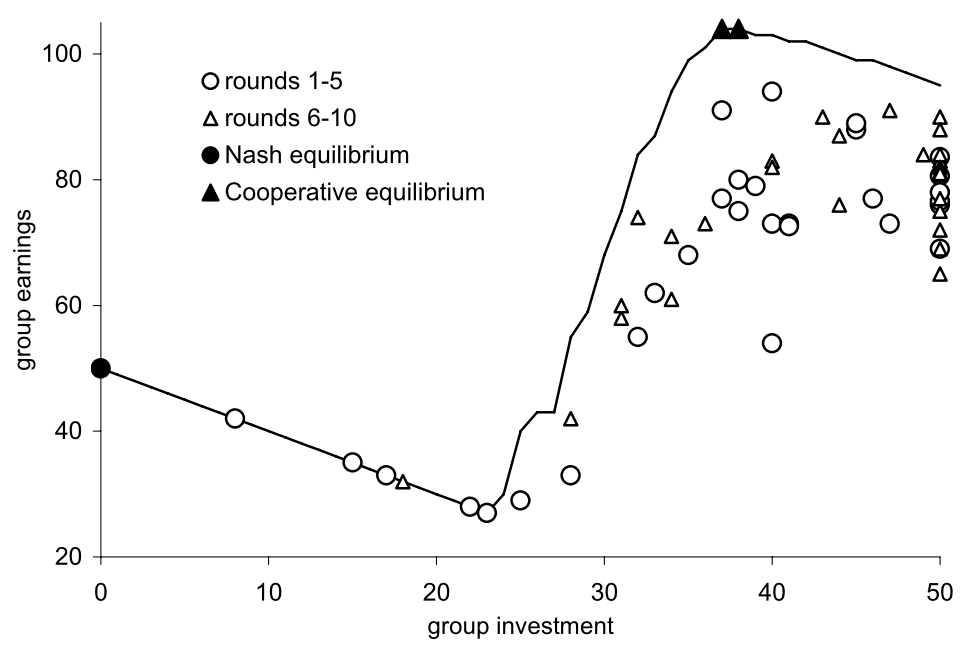

Fig. 6 The relation between the group investment and group earnings for each round of the five person experiments. Distinction is made between data from first half and second half of the experiment

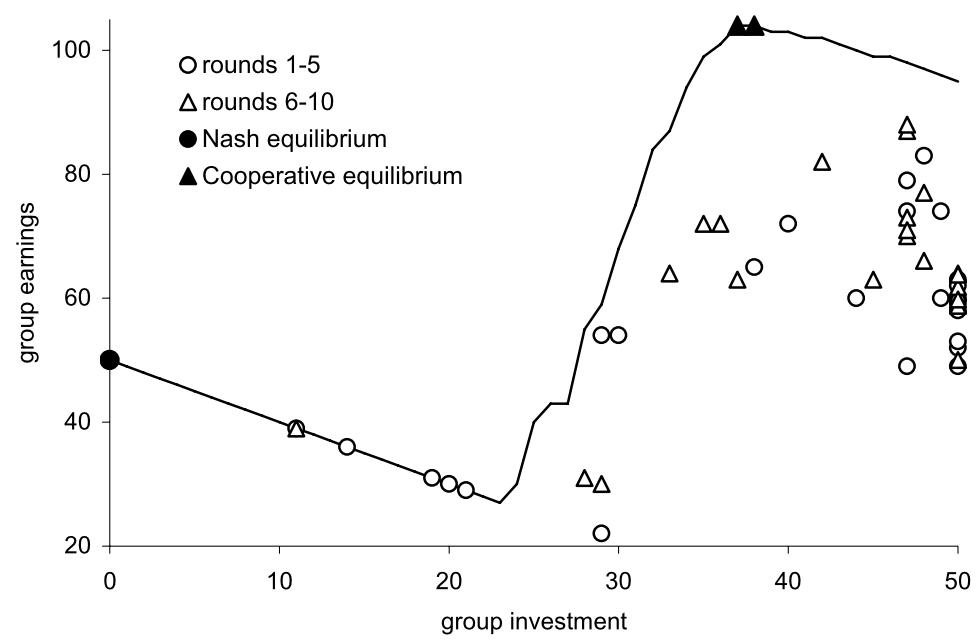

Fig. 7 The relation between the group investment and group earnings for each round of the five person (b) experiments. Distinction is made between data from first half and second half of the experiment

We also see that the returns are above the Nash equilibrium due to the high level of investment in the bandwidth.

Treatments with five persons involve increased difficulty for subjects to coordinate file downloads, especially when a partly downloaded file can be lost. Note also that in $35 \%$ of the cases, all five players invest the maximum in the public infrastructure but this does not lead to the maximum earnings for the group. In the third treatment (Fig. 7) none of the groups achieve a joint earnings level of more than $85 \%$ of the 
Table 8 Regression results of number of tokens invested in bandwidth by individuals. Between brackets are the $p$ values

\begin{tabular}{|c|c|c|c|}
\hline & 2 persons & 5 persons & 5 persons (b) \\
\hline Constant & $10.388^{* * *}(2.543)$ & $8.417^{* * *}(0.940)$ & $\mathbf{8 . 1 2 5}^{* * *}(1.217)$ \\
\hline $\begin{array}{l}\text { Share from } \\
\text { downloading } \\
(t-1)\end{array}$ & $-3.969(4.932)$ & $-5.487^{* *}(2.464)$ & $-1.485(3.038)$ \\
\hline $\begin{array}{l}\text { Share from } \\
\text { downloading } \\
(t-1)^{*} \text { position }\end{array}$ & $12.446^{* * *}(3.142)$ & $3.836 * * *(0.836)$ & $2.884^{* *}(1.008)$ \\
\hline Position $(A=1, E=5)$ & $-6.265^{* * *}(1.579)$ & $-1.007^{* * *}(0.179)$ & $-0.639^{* * *}(0.225)$ \\
\hline Round & $0.067 * *(0.028)$ & $\mathbf{0 . 3 0 3}^{* * *}(\mathbf{0 . 0 5 1})$ & $0.145^{* *}(0.065)$ \\
\hline - Log Likelihood & 261.492 & 600.848 & 529.670 \\
\hline$N$ & 180 & 270 & 225 \\
\hline Number of groups & 10 & 6 & 5 \\
\hline \multicolumn{4}{|l|}{$\begin{array}{l}\text { Variance } \\
\text { components }\end{array}$} \\
\hline Individual level $\left(\sigma^{2}\right)$ & $0.973(0.053)$ & $2.175(0.095)$ & $2.489(0.120)$ \\
\hline Group level $\left(\tau_{00}\right)$ & $0.794(0.203)$ & $1.458(0.485)$ & $1.652(0.614)$ \\
\hline$\chi^{2}$ & $59.21(p=0.000)$ & $68.44(p=0.000)$ & $54.84(p=0.000)$ \\
\hline
\end{tabular}

*** $p<0.01,{ }^{* *} p<0.05,{ }^{*} p<0.1$

cooperative strategies. Positive reaction times and lost files due to interrupted connections lead to a lower number of files being downloaded by downstream subjects.

An analysis of the messages exchanged during the chat sessions provides some insights into the coordination efforts of the groups. On average, each subject exchanges 4.0 messages in the 2 person experiment and 3.4 messages in 5 person experiment during each 60 second chat session. In the analysis of the chat data we observe that the discussion was dominated by questions of how much to invest, especially in the early rounds. Not all groups discussed the issue of coordination of downloading, but if they did, the discussion tended to occur in later rounds and typically focused on the maximum number of files each should download, the order in which subjects should download, or strategies regarding how much time to wait before downloading the next file. In many cases, there was considerable discussion concerning the fact that downstream subjects tend to receive lower earnings compared to the upstream subjects. Some participants called for giving everybody a fair share of the downloading time, and some downstream participants threatened to invest less or nothing in the public infrastructure if they would not get a better opportunity to download files. Interestingly, those threats often illicit responses suggesting that it is only fair if everybody invests in the public infrastructure.

Since we have data at the individual and group level, where group level error rates might be influenced by individual level decisions we use a hierarchical linear model which allows us to control for variability of individuals within a group as well as group specific error rates. We ran the hierarchical linear model with investment levels in the public infrastructure as the dependent variable and with the position 
Table 9 Regression results of number of tokens earned by downloading by individual subjects. The standard deviation is shown in brackets

\begin{tabular}{|c|c|c|c|}
\hline & \multicolumn{3}{|c|}{ Tokens earned by downloading } \\
\hline & 2 person & 5 person & 5 person $(b)$ \\
\hline Constant & $9.634^{* *}(4.363)$ & $\mathbf{7 . 4 6 6}^{* * *}(\mathbf{2 . 0 7 4})$ & $5.128^{*}(2.647)$ \\
\hline Bandwidth & $0.398^{* * *}(0.053)$ & $0.379^{* * *}(0.025)$ & $0.317^{* * *}(0.032)$ \\
\hline Position $(\mathrm{A}=1, \mathrm{E}=5)$ & $-10.050^{* * *}(2.370)$ & $-3.150 * * *(0.486)$ & $-1.936 * * *(0.596)$ \\
\hline Round & $0^{2223}{ }^{* *}(0.094)$ & $0^{176}{ }^{*}(0.104)$ & $0.090(0.113)$ \\
\hline Share Contribution & $-8.674(6.900)$ & $-11.489(7.394)$ & $-0.247(8.634)$ \\
\hline $\begin{array}{l}\text { Share Contribution* } \\
\text { position }\end{array}$ & $9.444^{* *}(4.583)$ & $5.719^{* *}(2.274)$ & $-0.046(2.773)$ \\
\hline - Log Likelihood & 551.584 & 902.578 & 750.744 \\
\hline$N$ & 200 & 300 & 250 \\
\hline Number of groups & 10 & 6 & 5 \\
\hline \multicolumn{4}{|l|}{$\begin{array}{l}\text { Variance } \\
\text { components }\end{array}$} \\
\hline Individual level $\left(\sigma^{2}\right)$ & $3.716(0.193)$ & $4.929(0.205)$ & $4.877(0.222)$ \\
\hline Group level $\left(\tau_{00}\right)$ & $2.043(0.562)$ & $0.087(1.683)$ & $0.986(0.537)$ \\
\hline$\chi^{2}$ & $30.13(p=0.000)$ & $0.00(p=0.491)$ & $3.26(p=0.036)$ \\
\hline
\end{tabular}

${ }^{* * *} p<0.01,{ }^{* *} p<0.05,{ }^{*} p<0.1$

of the individual, the round number, and the relative share of tokens earned from resource extraction in the previous round as independent variables. We used Stata 10.0 and the command xtmixed for the estimation procedure (Rabe-Hesketh and Skrondal 2008). The data in Table 8 shows the individual level analysis of investment behavior. We found the same relations for all three treatments.

If one analyzes the multiple effects of both position and share of downloading, we see that participants' responses depend on their position. The participant in position A reduces their investment with higher shares of the common resources exploited, at least for the 5-person standard experiment. However, if participants downstream experience a large share of the earnings from downloading files in the previous round they tend to invest more (Share from downloading $(t-1)^{*}$ position). This indicates that if downstream participants do not get a significant share of the common resource, they do not maintain the same investment level. This reciprocity relationship supports Conjecture 2. The investment levels increase over the rounds, likely due to improved coordination within the groups.

The number of tokens earned from downloading is an indicator of the success of coordination, given a particular level of bandwidth. In Table 9 we see that more bandwidth leads to more tokens earned from downloading files and, additionally, groups improve their earnings over the rounds. This indicates that the improvement of earnings is due to improved coordination in the timing of file downloads for 2-and 5-person experiments. As expected, downstream participants receive a lower number 
Table 10 Regression results of number of tokens invested in bandwidth by groups. Between brackets are the standard deviations. The last column represents results of the relative fraction of tokens invested (of maximum possible)

\begin{tabular}{|c|c|c|c|c|}
\hline & 2 persons & 5 persons & 5 persons $(b)$ & All \\
\hline Constant & $16.057^{* * *}(0.806)$ & $49.085^{* * *}(7.024)$ & $41.735^{* * *}(5.873)$ & $0.822^{* * *}(\mathbf{0 . 0 4 8})$ \\
\hline Round & $0.064(0.096)$ & $1.390 * * *(0.474)$ & $0.809 *(0.490)$ & $\mathbf{0 . 0 1 3}^{* * *}(\mathbf{0 . 0 0 5})$ \\
\hline Fraction male & $1.712 *(0.940)$ & $-23.545^{* *}(10.741)$ & $7.622(8.253)$ & $0.110^{* *}(0.051)$ \\
\hline $\begin{array}{l}\text { Fraction econ } \\
\text { major }\end{array}$ & $-5.616^{* * *}(1.822)$ & $-3.979(9.208)$ & $-3_{1.023}^{* *}(7.836)$ & $-0.274^{* * *}(\mathbf{0 . 0 7 8})$ \\
\hline $\begin{array}{l}\text { Gini collection } \\
(t-1)\end{array}$ & $-0.048(3.361)$ & $-13.006^{*}(7.366)$ & $-19.673^{* *}(9.425)$ & $-0.432^{* * *}(0 . .091)$ \\
\hline $\begin{array}{l}\text { Persons }(2=1 \\
5=0)\end{array}$ & & & & $-0.055^{*}(0.034)$ \\
\hline $\begin{array}{l}\text { Break }(\text { yes }=1, \\
\text { no }=0)\end{array}$ & & & & $-0.010(0.033)$ \\
\hline - Log likelihood & 201.687 & 194.498 & 159.933 & 75.098 \\
\hline$N$ & 89 & 54 & 45 & 188 \\
\hline
\end{tabular}

*** $p<0.01,{ }^{* *} p<0.05,{ }^{*} p<0.1$

of tokens from downloading files, as they are disadvantaged by the reduced access to the bandwidth

There is an insignificant effect between share of tokens contributed to public infrastructure and the number of tokens earned from downloading. However, if this share of token contribution is multiplied by the position of the participant, we find that contributions of participants downstream are rewarded by more points earned from downloading. Downstream participants will derive increased earnings from downloading files if it had a higher share of contributions than upstream participants to the common infrastructure, but this increase does not counter the downstream effect itself. For example, in the 5-person experiment being one position further downstream leads to an average reduction of 3.15 points. However, participants in downstream positions gain only 0.57 points when their share of contributions is $10 \%$ higher than the other participants. For example, to overcome the loss incurred by being one position downstream, a participant would have to have a $60 \%$ higher share of investment in the common infrastructure than the person upstream-since $6^{*} 0.57>3.15$. Given the payoff structure, this would mean that less than 20 tokens would have been invested in the common infrastructure and no functioning infrastructure would have been provided. This effect is not significant for the case for the 5-person experimental treatments in which files must be downloaded uninterrupted.

Since participants communicate and interact in real time in the downloading component of the experiments, some dynamics may only be observed at the group level. Therefore we also performed an analysis at the group level as reported in Tables 10 and 11. The data in Table 10 shows that having more economics majors in the group leads to lower investment levels. Using the Gini coefficient of the number of tokens earned in the previous round as a measure for equality, the data in Table 9 shows that inequality of earnings from downloading files leads to lower levels of investment 
Table 11 Regression results of number of tokens earned by downloading files by groups. The standard deviations are shown in brackets. The last column combines all treatments and looks at the relative fraction of tokens earned from total possible tokens

\begin{tabular}{|c|c|c|c|c|}
\hline & 2 persons & 5 persons & 5 persons $(b)$ & All \\
\hline Constant & $-2.711(3.438)$ & $4.225(6.148)$ & $-20.093^{*}(10.230)$ & $-0.024(0.053)$ \\
\hline Round & $0.475^{* * *}(0.167)$ & $0.560(0.347)$ & $0.423(0.442)$ & $0.007^{* * *}(\mathbf{0 . 0 0 3})$ \\
\hline Bandwidth & $0.790 * * *(0.085)$ & $2.152^{* * *}(\mathbf{0 . 1 7 2})$ & $2.020 * * *(0.278)$ & $0.020 * * *(0.001)$ \\
\hline Fraction male & $-2.519(1.544)$ & $-28.212^{* * *}(7.862)$ & $1.766(8.556)$ & $-0.085^{* * *}(0.029)$ \\
\hline $\begin{array}{l}\text { Fraction econ } \\
\text { major }\end{array}$ & $-6.018^{*}(3.290)$ & $-8.608(7.723)$ & $-23.092^{* * *}(\mathbf{8 . 6 0 1})$ & $-0.077(0.048)$ \\
\hline Gini contribution & $-24.659^{* *}(11.170)$ & $18.409(14.225)$ & $44.457^{* *}(18.900)$ & 0.1420 .101 \\
\hline $\begin{array}{l}\text { Persons }(2=1 \\
5=0)\end{array}$ & & & & $-0.039 * *(0.019)$ \\
\hline $\begin{array}{l}\text { Break }(\text { yes }=1, \\
\text { no }=0)\end{array}$ & & & & $-0.120 * * *(0.020)$ \\
\hline - Log likelihood & 294.174 & 199.957 & 176.864 & 179.620 \\
\hline$N$ & 100 & 60 & 50 & 210 \\
\hline
\end{tabular}

in the 5-person groups. Those who received fewer tokens than others reduced their investment in the provision of public infrastructure (see also Table 8).

The tokens earned by groups improve over the rounds which confirm the improved coordination as found on the individual level (Table 11). Groups with more males and more economics majors tend to lead to fewer tokens being earned in the downloading phase. This may indicate that the male participants perceive the downloading phase as a competitive environment in which they behave more selfishly (Gneezy et al. 2003). The Gini coefficient for the contributions in the investment phase of the round has no conclusive impact. For 2-person experiments, we find that inequality in contributions leads to a lower number of tokens being earned during the downloading phase of the round. This may suggest that the position A participant does not give participant B much bandwidth when (s)he invested more than participant B. In the 5-person experiments we observe that higher inequality in contributions leads to higher numbers of tokens earned in the downloading phase. A possible explanation of this behavior is found in some of the text chat discussions. The chat data suggests that groups allow the downstream participants to invest less to compensate for the losses in the early rounds of the experiment, while also improving the coordination of downloading files. The improved coordination of downloading is measured by increased earnings of tokens that cannot be explained by more bandwidth availability alone. Groups who need to download files uninterrupted to receive points earn significantly less tokens.

\section{Discussion}

This paper reports on a series of experiments we performed that focused on the asymmetric nature of the appropriation of a resource facilitated by public infrastructure which mimics dilemma situations related to irrigation. We observe that subjects invest significant amounts to generate the public infrastructure and that this increases 
over time. Subjects who are upstream have more control and appropriate more of the resource made available via the public infrastructure than those subjects downstream. There is the possibility for downstream subjects to indirectly punish the selfish behavior of upstream subjects through lower investment in subsequent rounds. We find a significant effect of this retaliation process on the performance of the groups both at the individual and group levels. In general we see more inequality in the number of tokens earned in the downloading phase than in the investment levels.

In the more complicated 5-person experiments, the improved performance over the rounds is due mainly to higher contribution levels to public infrastructure as the rounds progress. This higher level of contributions is a consequence of more equal distribution of earnings from downloading files. On the other hand, the improvements in earnings in the 2-person experiments are the consequence of improved coordination of downloading the files.

Asymmetric commons dilemmas explicitly include the inequality of access to the common-pool resource. Participants with better access to the public infrastructure also appropriate a greater share of the resources it makes available. Despite the inequality in earnings derived from utilization of the public infrastructure, there is only modest inequality in investments in generating the public infrastructure. Consistent with Rapoport (1997) participants tend to accept the fact that order of access affects the extraction levels. However, communication can lead to improved coordination and efficiency, and higher equality of the earnings. As such, equality of earnings leads to more efficient outcomes.

Taken together, these findings provide some insights into why Conjecture 4 , the under provision of the public infrastructure due to the asymmetric nature of the resource extraction, typically does not hold. Specifically, such asymmetric commons dilemmas do not come to exist in a vacuum. There are subtle contextual and historical variables that condition these situations as they occur in the real world. For example, irrigation systems develop over time with head-enders often arriving before tail-enders and exploiting the best land. The infrastructure is built over time as the system expands to serve ever more marginal lands. Tail-enders know before the "game" begins that their access to water will be asymmetric and during times of scarcity to expect that they will not receive water and should plan accordingly (Cifdaloz et al. 2010). In systems that have developed in this way, this asymmetry is perceived as "fair" as long as fairness is observed more generally in the overall operation of the system (e.g. tail-enders may be required to invest less labor in canal maintenance because they receive less water). Our experiments suggest that these ingredients, acceptance of order of access and perceptions of fairness, may be fundamental for the survival of social-ecological systems that we would otherwise not expect to do so if based on rational self-interested behavior (Camerer and Fehr 2006).

Acknowledgements We acknowledge support from the National Science Foundation (BCS-0527744 and BCS 0601320) and comments from Elinor Ostrom, James Walker and two anonymous reviewers.

\section{References}

Balliet, D. (2010). Communication and cooperation in social dilemmas: a meta-analytic review. The Journal of Conflict Resolution, 54, 39-57. 
Bochet, O., Page, T., \& Putterman, L. (2006). Communication and punishment in voluntary contribution experiments. Journal of Economic Behavior \& Organization, 60(1), 11-26.

Budescu, D. V., \& Au, W. T. (2002). A model of sequential effects in common pool resource dilemmas. Journal of Behavioral Decision Making, 15, 37-63.

Camerer, C. F., \& Fehr, E. (2006). When does "Economic Man" dominate social behavior? Science, 311, 47-52.

Cifdaloz, O., Regmi, A., Anderies, J. M., \& Rodriguez, A. A. (2010). Understanding robustness in smallscale social-ecological systems: the Pumpa Irrigation System in Nepal. Ecology and Society, 15(3), 39.

Croson, R. T. A., \& Marks, M. B. (2000). Step returns in threshold public goods: a meta- and experimental analysis. Experimental Economics, 2(3), 239-259.

Fehr, E., \& Gächter, S. (2000). Cooperation and punishment in public goods experiments. The American Economic Review, 90, 980-994.

Gneezy, U., Niederle, M., \& Rustichini, A. (2003). Performance in competitive environments: gender differences. Quarterly Journal of Economics, 1049-1074.

Hackett, S., Schlager, E., \& Walker, J. M. (1994). The role of communication in resolving commons dilemmas: experimental evidence with heterogeneous appropriators. Journal of Environmental Economics and Management, 27(2), 99-126.

Hunt, R. C. (1988). Size and structure of authority in canal irrigation systems. Journal of Anthropological Research, 44(4), 335-355.

Isaac, R. M., \& Walker, J. M. (1988a). Group size effects in public goods provision: the voluntary contribution mechanism. The Quarterly Journal of Economics, 103, 179-200.

Isaac, R. M., \& Walker, J. M. (1988b). Communication and free-riding behavior: the voluntary contributions mechanism. Economic Inquiry, 585-608.

Isaac, R. M., Walker, J. M., \& Williams, A. W. (1994). Group size and the voluntary provision of public goods: experimental evidence utilizing large groups. Journal of Public Economics, 54(1), 1-36.

Janssen, M. A., Holahan, R., Lee, A., \& Ostrom, E. (2010). Lab experiments to study social-ecological systems. Science, 328, 613-617.

Janssen, M. A., Bousquet, F., Cardenas, J. C., Castillo, D., \& Worrapimphong, K. (2011). Field experiments on irrigation dilemmas (submitted).

Lansing, J. S. (1991). Priests and programmers: technologies of power in the engineered landscape of Bali. Princeton: Princeton University Press.

Ledyard, J. O. (1995). Public goods: a survey of experimental research. In J. Kagel \& A. Roth (Eds.), The handbook of experimental economics (pp. 111-194). Princeton: Princeton University Press.

Ostrom, E. (1992). Crafting institutions for self-governing irrigation systems. San Francisco: ICS Press.

Ostrom, E., Walker, J. M., \& Gardner, R. (1992). Convenants with and without a sword-self-governance is possible. The American Political Science Review, 86(2), 404-417.

Ostrom, E., \& Gardner, R. (1993). Copying with asymmetries in the commons: self-governing irrigation systems can work. The Journal of Economic Perspectives, 7(4), 93-112.

Rabe-Hesketh, S., \& Skrondal, A. (2008). Multilevel and longitudinal modeling using stata (2nd ed.). College Station: Stata Press.

Rapoport, A. (1997). Order of play in strategically equivalent games in extensive forms. International Journal of Game Theory, 26, 113-136.

Wittfogel, K. A. (1957). Oriental despotism: a comparative study of total power. New Haven: Yale University Press. 